\title{
Long-term phonological learning begins at the level of word form
}

\author{
Anni Nora a,b,*,1, Annika Hultén ${ }^{\text {a,c, } 1}$, Leena Karvonen ${ }^{a}$, Jeong-Young Kim ${ }^{\text {d }}$, Minna Lehtonen a,c,e \\ Hely Yli-Kaitala ${ }^{b}$, Elisabet Service ${ }^{\text {b,f }}$, Riitta Salmelin ${ }^{\text {a }}$ \\ a Brain Research Unit, O.V. Lounasmaa Laboratory, Aalto University, Espoo, Finland \\ b Cognitive Science, Institute of Behavioral Sciences, University of Helsinki, Helsinki, Finland \\ c Department of Psychology and Logopedics, Abo Akademi University, Turku, Finland \\ d Institute for Asian and African Studies, University of Helsinki, Helsinki, Finland \\ e Cognitive Brain Research Unit, Cognitive Science, Institute of Behavioral Sciences, University of Helsinki, Helsinki, Finland \\ ${ }^{\mathrm{f}}$ Department of Linguistics and Languages, McMaster University, Hamilton, Canada
}

\section{A R T I C L E I N F O}

\section{Article history:}

Accepted 13 July 2012

Available online 23 July 2012

\section{Keywords:}

Auditory perception

Speech production

Nonword repetition

MEG

Language learning

\begin{abstract}
A B S T R A C T
Incidental learning of phonological structures through repeated exposure is an important component of native and foreign-language vocabulary acquisition that is not well understood at the neurophysiological level. It is also not settled when this type of learning occurs at the level of word forms as opposed to phoneme sequences. Here, participants listened to and repeated back foreign phonological forms (Korean words) and new native-language word forms (Finnish pseudowords) on two days. Recognition performance was improved, repetition latency became shorter and repetition accuracy increased when phonological forms were encountered multiple times. Cortical magnetoencephalography responses occurred bilaterally but the experimental effects only in the left hemisphere. Superior temporal activity at 300-600 ms, probably reflecting acoustic-phonetic processing, lasted longer for foreign phonology than for native phonology. Formation of longer-term auditory-motor representations was evidenced by a decrease of a spatiotemporally separate left temporal response and correlated increase of left frontal activity at 600-1200 ms on both days. The results point to item-level learning of novel whole-word representations.
\end{abstract}

(c) 2012 Elsevier Inc. All rights reserved.

\section{Introduction}

When we encounter a new spoken language we often try to pronounce the novel phonological forms. Indeed, acquisition of new phonological representations mostly occurs through repeated exposure to and attempted production of the perceived word forms, without explicit memorization. When the new word forms adhere to a completely foreign phonological system, generalizable phonotactic rules become available after sufficient exposure, based on statistical probabilities in the input. The present study addresses the behavioral and neural correlates of phonological learning in the native and a foreign language in an ecologically valid, natural language learning paradigm, using overt repetition. This type of task does not require explicit memorization of the items, but allows examination of the neural patterns during perception of the word form that are related to formation of phonological representations required for later reproduction. A comparison of novel word forms complying either with the rules of the native language or a foreign language is used to reveal whether the observed pattern of learning is related to the learning

\footnotetext{
* Corresponding author at: Brain Research Unit, O.V. Lounasmaa Laboratory, Aalto University, P.O. Box 15100, FI-00076 AALTO, Finland. Fax: + 358947023508.

E-mail address: anni.nora@aalto.fi (A. Nora).

1 The authors contributed equally to this study.
}

of the foreign phonological system or the learning of individual word forms.

Successful repetition of single pseudowords and meaningless verbal sequences is viewed as a measure of phonological working memory capacity, and it has been established as an important probe of language learning abilities in both first and second languages (Gathercole and Baddeley, 1989; Service, 1992). Pseudoword repetition is especially predictive of learning new vocabulary early in the learning process (French, 2006; Service and Kohonen, 1995). In addition to phonological storage capacity, repetition of pseudowords and learning to recognize and produce novel words are also thought to rely on auditory-perceptual processing, extraction of the phonological structure of the utterance, translation of phonology to motor output code and execution of the resulting articulatory sequence (Gathercole, 2006). Longer-term representations of individual word forms arise and develop through processing in a perceptionproduction loop: Active reproduction (rote rehearsal) of new phonological forms, either overtly or covertly, improves learning as compared with non-verbal strategies (Ellis and Beaton, 1993) or conditions in which rehearsal is prevented (Ellis and Beaton, 1993; Papagno et al., 1991).

Many previous experimental studies have demonstrated that artificially simple phonotactic regularities can be extracted from auditory input by both adults and infants after remarkably little exposure 
(Saffran et al., 1996, 1997). Further, incidental learning from an auditory stream has been found to influence repetition performance for new pseudowords adhering to such generalized rules in both adults and 8-year-olds (Majerus et al., 2004). The learning of phonotactic patterns, resulting in the reduction of speech errors, may be enhanced by motor involvement. A study by Warker et al. (2009) observed such learning effects only after overt production in the training phase. However, infant studies show that representation of the statistical structure of the more complex phonotactic system of a natural language can be detected at the age of nine months (Friederici and Wessels, 1993; Jusczyk et al., 1993, 1994), before overt production of words. So far, very little is known about how phonotactic acquisition first begins in a second language.

Phonological learning has mostly been studied in first language (L1) pseudowords, thus, a process akin to expansion of the vocabulary in the mother tongue (e.g. Graves et al., 2008; Rauschecker et al., 2008). Pseudoword repetition in an unfamiliar language, in contrast, is expected to reveal how phonological sensitivity begins to emerge in a new language. Behavioral studies (e.g. Thorn and Gathercole, 1999) have shown that storing phonological information in memory is easier if the input follows the phonotactic regularities of phoneme combinations in the native language. In this case, no additional processing is required for coding unfamiliar sound combinations (Gathercole, 1995). In addition to easier acoustic-phonetic processing and short-term memory maintenance, there is a memory reconstruction advantage in the production/recall of new native language items with imperfect representations. Based on the repetition accuracy of nonwords manipulated on both phonetic and phonological levels, it has been suggested that familiar phonetic knowledge mainly facilitates perceptual analysis, whereas familiarity of phonological/phonotactic structures plays a larger role in reconstructive processes during retrieval (Kovács and Racsmány, 2008).

Reconstruction effects could rise either from lexical or lexicalsemantic neighborhood effects or from sublexical phonotactic knowledge (Gathercole et al., 1999; Majerus et al., 2004), supporting incompletely encoded or missing phonetic material. Some studies of spontaneous L1 vocabulary learning have differentiated between two correlated properties of word forms: phonotactic probability (the frequency with which an item's phonemes occur in the same syllable position in other words, and before and after the same phonemes in other words) and neighborhood density (how many words differ from the item only by one phoneme, and how frequent these are) (Storkel et al., 2006; Storkel, 2009; Storkel and Lee, 2011). Those studies have suggested that phoneme patterns occurring infrequently may be more likely to trigger initial (possibly imperfect) formation of word form representations, whereas later memory consolidation and integration is easier when the new word has many phonological neighbors. The present study explored the first phase of phonological learning in an authentic L2 in learners with no pre-existing lexicon or knowledge of L2-specific phonotactic constraints. Thus, at the outset of the present study, there could be no lexical neighbors (even based on L1 because two unrelated languages were studied), and phonological and phonotactic expectations could only be based on L1.

It continues to be debated whether acquisition of novel word forms is driven by existing lexical content or acquired general sublexical rules. Studies of early native language acquisition (Friederici and Wessels, 1993; Jusczyk et al., 1993, 1994) suggest that prior to lexical development infants are aware of the predominant stress patterns, word boundaries and typical phoneme combinations in their native language, which later facilitates the acquisition of lexical word forms. However, pseudoword repetition tasks (Edwards et al., 2004; Zamuner, 2009) have shown that children are more accurate and fluent in their production of phonemes in the context of target sequences that occur frequently in real words, and that children with larger vocabularies perform better. Such findings provide support for the view that the process of phonological learning in a novel phonological system might proceed as item-based learning at the level of individual word forms until the lexicon is large enough to support statistical rule extraction, similarly as what seems to be the case in artificial grammar learning (Forkstam et al., 2008). Recent theories of phonological development (Pierrehumbert, 2003) propose that phoneme units of language are abstracted from exemplar sounds in specific positions within a syllable (for instance, the consonant $/ \mathrm{k} /$ as syllable-initial, as in /kæt/, as opposed to syllable-final, as in /bæk/). A learner may acquire new phonological patterns by encoding rough memory representations for word forms when they encounter them for the first time, and on subsequent encounters use these initially underspecified representations as top-down scaffolding to support more accurate encoding of the phonological patterns.

The current study aimed to characterize the online formation of novel phonological representations, tracking cortical dynamics with magnetoencephalography (MEG) during word perception. To help explore whether the effects seen during the first stages of foreign language learning are related to acquisition of specific phonological forms or more general learning of phonotactic structures, the stimuli included both native (Finnish) pseudowords and words of a foreign phonological structure (Korean). Korean and Finnish have different phonemic systems and they differ considerably in their typical syllable structure. For this reason, native Finnish speakers experience difficulty perceiving and producing unfamiliar Korean phoneme contrasts (Kim, 2010). If learning in a foreign phonological system is initially restricted to establishing memory traces for individual words, and phonotactic rules are extracted only later, the pattern of learning foreign language word forms may initially resemble that of learning novel L1 word forms, presumably reflected as diminished brain responses for recurring word forms in both languages (Graves et al., 2008; Majerus et al., 2005; Rauschecker et al., 2008). However, if the learner is exploring hypotheses about novel phonotactic regularities from the start, repeated exposure to the foreign language could result in generalized effects to both recurring stimuli and words encountered for the first time in the new language. No such effects would be expected to pseudowords with an L1 phonotactic structure, as these reflect the same statistical relationships as in L1 words in general. The generalized effects of rule learning in the new phonological system could appear, for example, as initially stronger activation to foreign language word forms that would later diminish and approach the activation level associated with the native language word forms (Zhang et al., 2005; for a review, see van Heuven and Dijkstra, 2010).

We sought to maximize the efficiency of phonological learning by using overt repetition of the auditorily presented items, with the same items recurring multiple times during the training session. This experimental choice was based on earlier reports on (i) improved learning of novel word forms by reproduction of the new phonological forms (Ellis and Beaton, 1993) and (ii) the effects of foreign phonemes and unfamiliar phonotactics affecting perception of the phoneme strings and reconstructive retrieval processes before preparation of production in repetition tasks (Kovács and Racsmány, 2008). The focus of this study was the formation of perceptual representations of novel phonological forms with increasing exposure to a new phonological system in one condition, and new word forms in the native phonological system in another, reflected in the modification of cortical responses. The reproductions of the participants were scored for accuracy to obtain a measure of learning performance, but this study was not primarily aimed at examining motor output of the novel word forms, or the emergence of phonetically accurate pronunciation with a native-like accent (see Kovács and Racsmány, 2008).

An initial behavioral experiment with sufficient statistical power verified that a paradigm with repeated exposure to a limited set of items was adequate to demonstrate learning in a foreign phonology and quantified the effects of this type of learning on repetition latency 
and accuracy. The main study using MEG addressed the cortical mechanisms associated with such learning effects. As one measure of learning, item recognition after the learning session was evaluated in both the behavioral and MEG experiments. In earlier functional magnetic resonance imaging (fMRI) and positron emission tomography (PET) studies, such 'repetition priming' designs have resulted in decreased activation in the left superior temporal cortex during one session, interpreted as a reflection of phonological processing and learning (Graves et al., 2008; Majerus et al., 2005; Rauschecker et al., 2008). As sleep has been suggested to be essential for the lexicalization of novel phonological representations (Dumay and Gaskell, 2007; Tamminen and Gaskell, 2008), our study also followed learning over two consecutive days.

\section{Materials and methods}

\section{Participants}

In the Behavioral experiment, the participants were 28 Finnishspeaking adults (18 females and 10 males; age 20-29 years, mean 24.4 years). Due to technical problems, two female participants were excluded from the analyses, and response latencies could not be obtained for two other participants. In the MEG experiment, the participants were 10 right-handed, Finnish-speaking adults (different from those in the behavioral experiment; 5 females and 5 males; age 21-44 years, mean 25.4 years). Handedness was established with an adapted version of the Edinburgh Handedness Inventory (Oldfield, 1971). All participants had normal hearing and no diagnosed neurological or language disorders. Participants gave their informed consent, in agreement with the prior approval of the local Ethics Committee.

\section{Stimuli}

In the Behavioral experiment, a set of 82 three-syllable, 82 four-syllable and 41 five-syllable Korean words or two-word combinations served as a stimulus pool. In the MEG experiment, in order to enhance the conformity of the neural responses and, thus, their sensitivity to experimental manipulation, the stimuli were limited to four-syllable items but the overall stimulus set was expanded to include 400 real Korean words or word combinations and 400 Finnish four-syllable pseudowords composed of two-syllable Finnish words no longer in use (Lönnrot, 1874-1880). These Finnish words were mostly nouns (some adjectives), and no inflected forms were included. Four-syllable words occur in both languages, and the results of the behavioral experiment showed similar learning effects for all three word-lengths. The duration of the four-syllable words in the MEG experiment varied from 862 to 1446 ms (mean 1130 ms) for Korean and from 1008 to 1490 ms (mean 1260 ms) for Finnish items.

The Korean words were all selected and digitally recorded by a female native Korean linguist, speaking standard Korean. The Finnish pseudowords in the MEG experiment were selected by the authors from an old dictionary (Lönnrot, 1874-1880) and recorded by a female native Finnish student of speech pathology. Korean and Finnish are phonologically markedly different. The Korean language has phoneme contrasts that do not exist in Finnish (e.g. Korean /t/ contrasts with $/ \mathrm{t}^{\prime} /$ and $/ \mathrm{t}^{\mathrm{h}} /$ ) and vice versa (e.g. $/ \mathrm{t} /$ and $/ \mathrm{d} /$ are different phonemes in Finnish, whereas in Korean they are allophones of a single phoneme). With $\mathrm{C}$ standing for consonant and $\mathrm{V}$ for vowel, possible syllables in Korean take the form $(\mathrm{C})(\mathrm{Glide}) \mathrm{V}(\mathrm{C})(\mathrm{C})$, e.g. myeng $(/ \mathrm{mj} / \mathrm{h} /)$ (K.-O. Kim and Shibatani, 1976), whereas the form in Finnish is $(C) V(V)(C)(C)$, e.g., the syllable mank (/mank*/) (Karlsson, 2003). In addition, stop and affricate sounds are categorized into three types in Korean but only into two in Finnish. Using Finnish pseudowords (instead of real words) in the MEG experiment ensured that the stimuli differed only in terms of novel vs. familiar phonology but that no meaning could be attributed to the stimuli of either language. All stimuli began with consonants, and stimuli in both languages contained equal numbers of nasal, fricative/affricate, and stop consonants as initial consonants in each stimulus category. The majority of Korean nouns, thus also most of the stimuli in the present study, begin with one of the stop or affricate consonants that do not exist in Finnish.

In the Behavioral experiment, words were recorded in 16-bit wav format using a sampling rate of $44 \mathrm{kHz}$. A 25 -ms ramp was added to the beginning and a 40-ms ramp to the end of each word. In the MEG experiment, an effort was made to equalize the stimuli, as much as possible, with respect to properties that are known to have a strong influence on early auditory cortical responses, such as stimulus intensity and rise time (Hari, 1990; Mäkelä and Hari, 1990) as well as length. The words were recorded in 24-bit wav format using a sampling rate of $48 \mathrm{kHz}$ and, to eliminate background noise, low-passed, on average, at $6 \mathrm{kHz}$ (gradual from $4 \mathrm{kHz}$ to $14 \mathrm{kHz}$ ). A 10-ms ramp was added to the beginning and end of each word.

\section{Design and procedure}

In the repetition task, the participants heard and repeated words that were presented once (Nonrecurring) or five times (Recurring). The Behavioral experiment was performed as a single session, whereas in the MEG experiment the measurement was conducted on two consecutive days for each language. In both experiments, presentation of the stimuli on Day 1 consisted of five blocks, each containing one presentation of the Recurring items, intermixed with $1 / 5$ of the Nonrecurring items. To control for the variation in difficulty between individual stimulus words, the recurring and non-recurring words were counterbalanced between participants as was the original order and reversed order of the stimuli. The participant's task was to listen to the words through headphones (in the Behavioral experiment) or a panel speaker (with $75 \mathrm{~dB}$ gain, in the $M E G$ experiment) and to repeat them as accurately as possible, mimicking also the speech rate. Participants were not instructed to memorize or learn the words in any way, only to repeat them as accurately as possible.

In the Behavioral experiment, there were 50 Recurring and 75 Nonrecurring Korean words in the repetition task. Both types of stimuli included equal proportions of all word lengths. During the session, participants were given 7 short breaks, unrelated to block boundaries. The participants' responses were recorded and the response latencies from stimulus onset to repetition onset were measured using an individually adjusted sound threshold. The Korean repetitions produced by the participants during all five blocks were rated ( 0 or 1 points per word/syllable) in a scrambled order by a native Korean speaker unaware of the experimental manipulations. Two different rating schemes were used. In the syllable-based scoring system, a point was given for every accurately repeated syllable regardless of its position. In word-based scoring, a point was given if the whole word had been accurately repeated. A word/syllable was judged to be correctly repeated only if none of the phonemes were omitted, replaced with other Korean phonemes or transposed. However, phonetically native-like articulation or prosody was not required, and detailed evaluation of acoustic-phonetic deviations was outside the scope of this study. This type of scoring is most commonly used in pseudoword repetition experiments investigating the formation of phonological working memory representations. It was chosen here because our main interest was to compare memory performance for the Recurring/Nonrecurring items across the session. As production errors for Korean items may have occurred because of failure to represent the items in memory or because of difficulties to produce the foreign phonemes, somewhat deviant or "accented" output was accepted as correct reproduction, following the practice in foreign word repetition research (see Kovács and Racsmány, 2008; Majerus et al., 2004). 
In the MEG experiment, all participants performed the same word repetition tasks in Korean and Finnish, in separate sessions, with the order of the languages counterbalanced between participants. For each language, MEG recordings were performed on two consecutive days to allow for memory consolidation, and 1-7 days passed between tests in the different languages; thus, there were altogether 4 days of MEG recordings per participant. On Day 1 (of each language), the participants heard and repeated 100 stimuli that were presented once (Nonrecurring) and 100 stimuli that were presented five times (Recurring), as described above. On Day 2, the Recurring and Nonrecurring items from Day 1, each presented once, were mixed with 200 completely new items (New) to control for possible effects of task familiarity and to further address general learning of phonological and phonotactic regularities in the new phonological system (Fig. 1). In each trial, after the stimulus presentation and $300 \mathrm{~ms}$ of silence, a 50 -ms beep prompted the participant to overtly repeat the item. Delayed repetition was used to avoid muscle artifact contamination in the MEG signal of interest. The delayed response procedure prevented us from recording response latencies. In the MEG experiment repetition accuracy was evaluated on a set of randomly selected four-syllable Korean and Finnish words (20 Recurring, 20 Nonrecurring) in the first and last (5th) blocks. Scoring was done on the word level, similar to the Behavioral experiment. The MEG recordings on Day 1 took approximately $40 \mathrm{~min}$ (including two short breaks) and on Day 2 approximately 30 min (including one or two breaks).

In both experiments, the word-repetition task was followed by a behavioral recognition task (on Day 2 in the MEG experiment) of which the participants had no advance knowledge. Participants heard a randomly selected subset of the words from Day 1 (70 in the Behavioral experiment and 50 in the MEG experiment, half of which were Recurring and half Nonrecurring) mixed with a matching number of words they had not heard before. The stimulus words were presented through headphones, and the participants' task was to indicate by a button press for each word if it had been presented before.

\section{MEG recording}

Magnetic fields associated with neural current flow were recorded in a magnetically shielded room with a 306-channel whole-head neuromagnetometer (Elekta Oy, Helsinki) in the Brain Research Unit MEG Core. The MEG signals were band-pass filtered between 0.03 and $200 \mathrm{~Hz}$ and sampled at $600 \mathrm{~Hz}$. Eye movements and blink artifacts were monitored by an electro-oculogram (EOG) and motor artifacts related to mouth movements by an electro-myogram (EMG).

\section{MEG data analysis}

The MEG analysis was focused on the perception phase. The signals were averaged from $200 \mathrm{~ms}$ before to $1200 \mathrm{~ms}$ after the stimulus onset, rejecting trials contaminated by eye movement, blink or mouth movement artifacts (percent of accepted trials $88 \pm 9.7 \%$, mean \pm SD). The averaged MEG responses were baseline-corrected to the 200-ms interval immediately preceding the stimulus onset and low-pass filtered at $40 \mathrm{~Hz}$. The sensor-level data reflect summation of multiple underlying sources. Two different types of analysis methods were used to reach from the sensors to the source-level spatiotemporal distribution of task-related neural activation.

For an overview of the distribution of neural activity, minimum current estimates (MCE) (Uutela et al., 1999) were computed separately for each individual and then averaged. A limitation of this method is that it cannot distinguish between multiple independent sources that are spatially proximate but have different dominant orientations of current flow, typical of auditory word processing (Bonte et al., 2006; Uusvuori et al., 2008). Therefore, separable cortical-level spatiotemporal components were estimated by means of guided current modeling (Equivalent Current Dipole modeling, ECD, Hämäläinen et al., 1993), where components explaining major local variance in the data were added until the model explained at least $80 \%$ of the total variance. This criterion led to the inclusion of 3-6 components per participant. For any one participant, the same set of ECD components represented well the data of both recording days and both languages. Following the standard procedure (Salmelin, 2010), the time courses of the identified spatiotemporal components (source waveforms) were estimated by fixing their location and orientation parameters while allowing their strengths to vary to best account for the signals detected by all MEG sensors over the entire analysis interval.

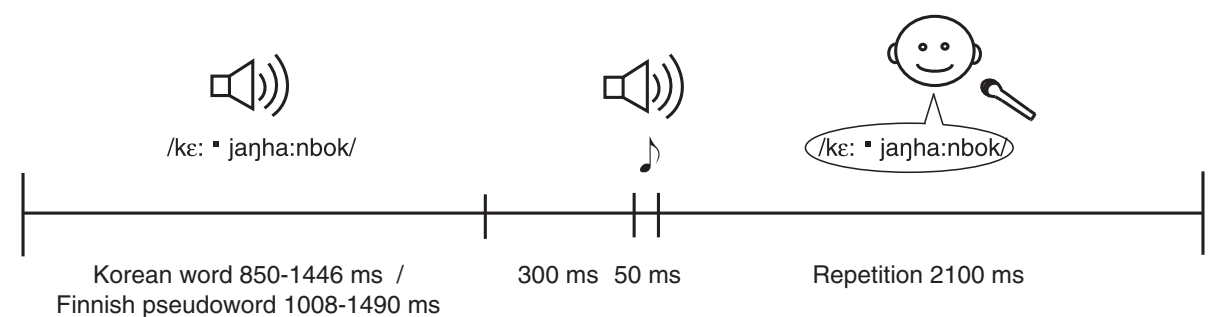

Day 1

Nonrecurring Recurring Nonrecurring Recurring New words

\begin{tabular}{|c|c|c|c|c|c|}
\hline \multirow[b]{2}{*}{ Korean ${ }^{*}$} & \multirow[b]{2}{*}{100} & \multirow[b]{2}{*}{$100(\times 5)$} & \multicolumn{3}{|c|}{ from Day 1} \\
\hline & & & 100 & 100 & 200 \\
\hline Finnish $^{*}$ & 100 & $100(x 5)$ & 100 & 100 & 200 \\
\hline
\end{tabular}

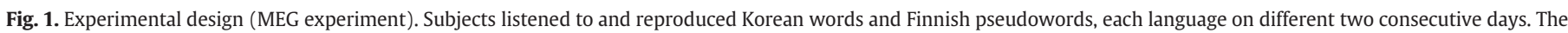

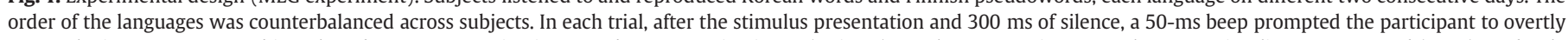

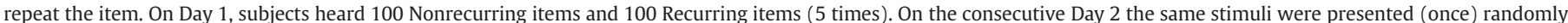

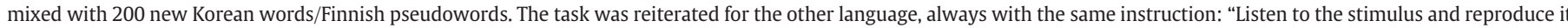

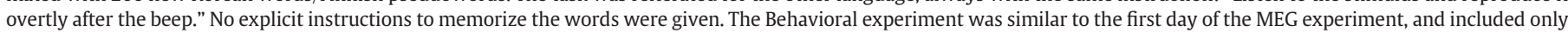
the presentation of 50 Recurring and 75 Nonrecurring Korean words (and no Finnish pseudowords) as stimuli. 
To locate the components anatomically, the center of activation of each component was displayed on the individual magnetic resonance images (MRI) of each participant. For group-level visualization, the locations were transformed to a standard brain (Roland and Zilles, 1996) using an elastic transformation (Schormann et al., 1996; Woods et al., 1998).

\section{Statistical analysis}

Recognition performance was evaluated as a discriminability measure, $d^{\prime}$, between previously heard and new words, taking into account the false alarm rate. It was calculated individually for each participant and separately for the Recurring and Nonrecurring words. In the Behavioral experiment, the results were analyzed with a repeatedmeasures $t$-test (Recurring vs. Nonrecurring words) and in the MEG experiment with a repeated-measures $2 \times 2$ (language $\times$ stimulus recurrence) ANOVA.

In the Behavioral experiment, repetition latency (from stimulus onset to repetition onset) and accuracy (proportion of correctly repeated words) were obtained for each presentation block, i.e., for each of the five presentations of the Recurring words and each $1 / 5$ of the Nonrecurring words, and analyzed using a repeated-measures $2 \times 5$ (stimulus type $\times$ stimulus block) analysis of variance (ANOVA).

In the MEG experiment (accuracy only, no reaction time data) with less statistical power, repetition accuracy was analyzed for the first and last (5th) blocks, i.e., for the first and fifth of the five presentations of the Recurring words and the $1 / 5$ of the Nonrecurring words presented during the first and fifth block, using a repeated-measures $2 \times 2 \times 2$ (language $\times$ stimulus type $\times$ stimulus block) ANOVA. Further planned pair-wise t-tests were Bonferroni corrected.

Statistical analysis of the cortical activity in the MEG experiment was performed on the ECD source waveforms. They were divided into a set of relevant time windows that covered the onset, peak and decline of the responses. The same time windows were used for all participants, except for a transient reduction of activity at about $200 \mathrm{~ms}$ that was described by the mean source strength in a 100 -ms wide window centered on the lowest point (defined separately for each participant). For estimating the effect of stimulus recurrence, the fifth presentation of the Recurring stimuli on Day 1 , their single (sixth) presentation on Day 2, the Nonrecurring stimuli of Day 1 and New stimuli of Day 2 were included in a repeatedmeasures $2 \times 2 \times 2$ ANOVA with the factors: language (Finnish vs. Korean), stimulus recurrence (first vs. fifth/sixth encounter) and experimental day (Day 1 vs. Day 2). Group-level analyses were conducted on spatiotemporally congruent components that also had a similar orientation of current flow. Clusters of comparable components identified in at least six participants were included in statistical comparisons (Table 1).

\section{Results}

\section{Recognition performance}

In the Behavioral experiment, participants recognized 44 vs. $25 \%$ (proportion of hits) of the Recurring vs. Nonrecurring Korean words $\left[\mathrm{d}^{\prime}=1.94\right.$ vs. 0.59 , Recurring items better than Nonrecurring; $\mathrm{t}(25)=$ 18.7, $\mathrm{p}<0.001]$. Very similar performance for the Korean stimuli emerged in the recognition test of the MEG experiment (Day 2): Participants recognized 44 vs. $22 \%\left(\mathrm{~d}^{\prime}=0.73\right.$ vs. 0.30$)$ of the Recurring vs. Nonrecurring Korean words and 71 vs. $30 \%\left(d^{\prime}=1.66\right.$ vs. 0.65$)$ of the Recurring vs. Nonrecurring Finnish pseudowords [Finnish better than Korean; $F(1,9)=8.9, p<0.05$ ] (Fig. 2A). Recurring items, encountered altogether six times over the two days, were recognized significantly better than Nonrecurring items that were encountered only once on each experimental day $[\mathrm{F}(1,9)=62.4, \mathrm{p}<0.001]$. Multiple presentations enhanced recognition more for the Finnish pseudowords than for the Korean words [interaction language-by-stimulus recurrence; $F(1,9)=10.5, p<0.01$.

\section{Repetition latency and accuracy}

The Behavioral experiment included Korean stimuli only. The repetition latency from stimulus onset to repetition onset (Fig. 2B) decreased with multiple presentations (from 1st to 5th block) $[\mathrm{F}(4$, $92)=17.6, \mathrm{p}<0.001]$, and more so for Recurring items than for Nonrecurring items [interaction block-by-stimulus type; F(4, 92)= 13.0, $\mathrm{p}<0.001]$. Overall, the repetition latency was shorter for Recurring words than for Nonrecurring words $[\mathrm{F}(1,23)=17.7, \mathrm{p}<0.001]$. During the last (5th) block, participants took on average $1477 \mathrm{~ms}$ (Recurring) vs. $1553 \mathrm{~ms}$ (Nonrecurring) to begin their repetition response [latency shorter for Recurring words, pair-wise t-test; $\mathrm{t}(47)=4.5, \mathrm{p}<0.001]$.

Repetition accuracy in the Behavioral experiment increased with multiple presentations (Fig. 2C). Scoring based on syllable- and word-level accuracy yielded similar results; only results of the word-based scoring are presented. Participants correctly repeated 58\% of the Recurring vs. $60 \%$ of the Nonrecurring words during the first block and 62 vs. 55\% during the fifth block. The proportion of correctly repeated words (repetition accuracy) was significantly higher for Recurring words than for Nonrecurring words $[F(1,25)=6.67, p<0.05]$. When all five blocks were included in the analysis, the interaction of presentation block and stimulus type approached significance $[F(4$, $22)=2.65, p=0.061]$, and became significant when only the 1 st and 5 th block were included $[F(1,25)=8.01, p<0.01]$, showing improved repetition accuracy for the Recurring words on the fifth compared to the first repetition [pair-wise $t$-test; $\mathrm{t}(25)=2.39, \mathrm{p}<0.05$ ]. Improvement from 1 st to 2 nd presentation was also significant [pair-wise $t$-test; $\mathrm{t}(25)=2.09, \mathrm{p}=0.047$ (Bonferroni corrected alpha $=0.025)$ ]. There was no reliable change in repetition performance for the Nonrecurring words during the session [pair-wise $t$-test for 1st and 5th presentation; $\mathrm{t}(25)=1.6, \mathrm{p}=0.12$ and 1 st and 2 nd presentation $\mathrm{t}(25)=$ $0.32, p=0.75$ ]. A $5 \times 3$ ANOVA crossing block with word length (three vs. four vs. five syllables) for the recurring words indicated a main effect of better performance for the shorter words $[F(2,25)=97.2$, $\mathrm{p}<0.0001$, but no reliable interaction with block $(\mathrm{F}<1)$, indicating equal improvement for short and long words.

In the MEG experiment, repetition performance was better for the Finnish pseudowords than for the Korean words $(F(1,7)=109.1$, $\mathrm{p}<0.01$ ). For the Finnish items, participants correctly repeated $78 \%$ of the Recurring vs. $80 \%$ of the Nonrecurring words during the first block and $76 \%$ vs. $82 \%$ during the fifth block. For the Korean items, participants correctly repeated $30 \%$ of the Recurring vs. $38 \%$ of the Nonrecurring words during the first block and 39 vs. 30\% during the fifth block. The changes in repetition performance from the first to the fifth block did not reach significance in this smaller sample $(F(1,7)=1.7, p=0.23)$, and performance was similar for Recurring and Nonrecurring items $(\mathrm{F}(1,7)=0.8, \mathrm{p}=0.40)$.

\section{Brain responses}

The spatiotemporal pattern of the MEG sensor-level signals was similar for all stimulus categories and across languages. Distributed source-level estimation (minimum current estimate, MCE) revealed a transient response bilaterally in the superior temporal cortex at about $100 \mathrm{~ms}$, followed by a strong sustained response from about $300 \mathrm{~ms}$ onwards (Fig. 3A). Another sustained response was observed over the left frontal cortex. Source-level analysis using Equivalent Current Dipole modeling allowed further decomposition of the activation in each temporal cortex into two functionally separate sources of neural current flow (Fig. 3B). Type I sources had a two-peaked structure, with the first, transient response reaching the maximum at $\sim 100 \mathrm{~ms}$ and the second, more sustained response at $400 \mathrm{~ms}$. When 
Table 1

Source-level cluster parameters.

\begin{tabular}{|c|c|c|c|c|}
\hline Source cluster & $\begin{array}{l}\text { Intersource distance in } \mathrm{cm} \\
(\text { mean }(\mathrm{SD}))\end{array}$ & $\begin{array}{l}\text { Direction in the tangential plane } \\
(\text { mean (SD)) }\end{array}$ & $\begin{array}{l}\text { Range } \\
(\min \ldots \max )\end{array}$ & Number of participants \\
\hline LT Type II & $2(0.9)$ & $102^{\circ}\left(34^{\circ}\right)$ & $64^{\circ} \ldots 151^{\circ}$ & 6 \\
\hline RT Type II & $1.5(0.6)$ & $52^{\circ}\left(41^{\circ}\right)$ & $-13^{\circ} \ldots 101^{\circ}$ & 6 \\
\hline
\end{tabular}

The ECD spatiotemporal components formed five distinct clusters: Left temporal (LT) Type I, left temporal Type II, left frontal (LF), right temporal (RT) Type I and right temporal Type II. The intersource distance was calculated between all pairs of sources within the cluster and averaged across subjects. Direction of current flow (mean, range) was defined in

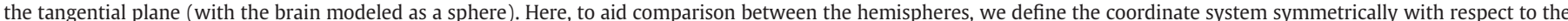

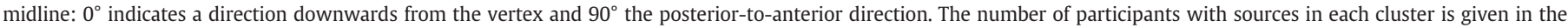
right-most column.

this response pattern was intermittently reduced, the Type II sources became transiently active, reaching the maximum at $~ 300 \mathrm{~ms}$. In individual subjects, these two types of temporal sources were also distinguishable based on their approximately perpendicular orientations of neural current flow, directed along the superior-inferior axis for the Type I sources and posterior-anterior axis for the Type II sources.

Type I temporal sources were identified bilaterally in all but one participant (who displayed a salient Type I source only in the right hemisphere) (Fig. 4A). Type II temporal sources were found in 6/10 participants in each hemisphere. An active source area in the left frontal cortex was also detected in 6/10 participants. For some participants, beyond the Type I activity, no salient frontal or Type II temporal activity could be identified in the field patterns and, thus, no corresponding neural source could be modeled. Table 1 summarizes the intersource distance, direction of the current flow and number of participants contributing to each source cluster.

Table 2 lists the statistical tests for the different types of cortical activation across time windows and Fig. 4 displays the significant effects as bar graphs. We chose a conservative approach for the statistical analyses, excluding missing cases listwise, i.e. performing the analysis on the group that was observed to have sources of a certain type. The earliest statistically significant effect was that of measurement day (similarly for both languages and the various stimulus types) in the left-hemisphere Type I temporal sources $[F(1,8)=6.1, p<0.05]$. The transient reduction of activation at about $200 \mathrm{~ms}$ was more marked on Day $2[6.7 \pm 2.7 \mathrm{nAm}$, mean $\pm \mathrm{SEM}]$ than on Day $1[7.9 \pm 2.9 \mathrm{nAm}]$.

Subsequently, at 300-600 ms, a main effect of language appeared in activation of the temporal Type II source cluster in the left hemisphere. The activation was stronger for Korean words than for Finnish pseudowords $[F(1,5)=7.5, p<0.05$, Korean $14.3 \pm 6.4$ nAm, Finnish $10.1 \pm 5.6 \mathrm{nAm}]$, i.e., activation returned to the base level more slowly for Korean stimuli than for Finnish stimuli. A significant interaction further emerged between stimulus recurrence and measurement day $[F(1,5)=7.5, p<0.05]$. Stimulus recurrence decreased the mean activation strength of the left temporal Type II sources during Day 1 [paired comparison: Recurring vs. Nonrecurring, $t(5)=2.9, \mathrm{p}<0.05$ ],
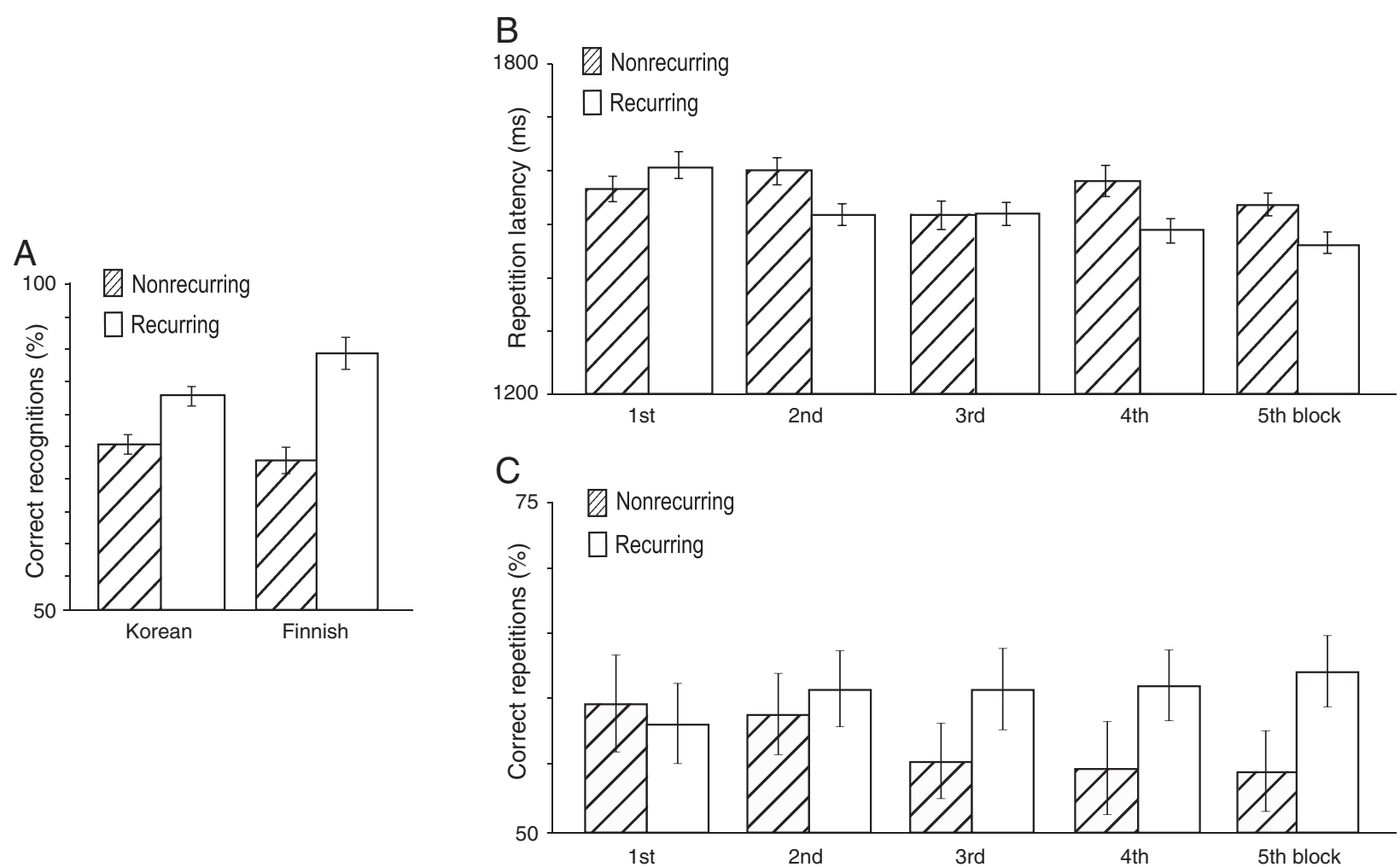

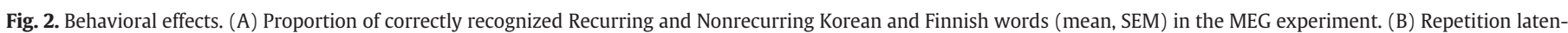

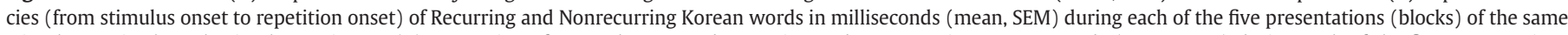

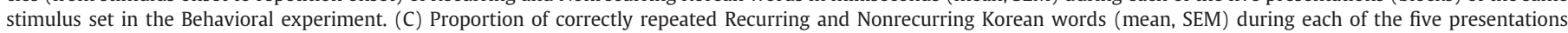
(blocks) of the same stimulus set in the Behavioral experiment. 
A

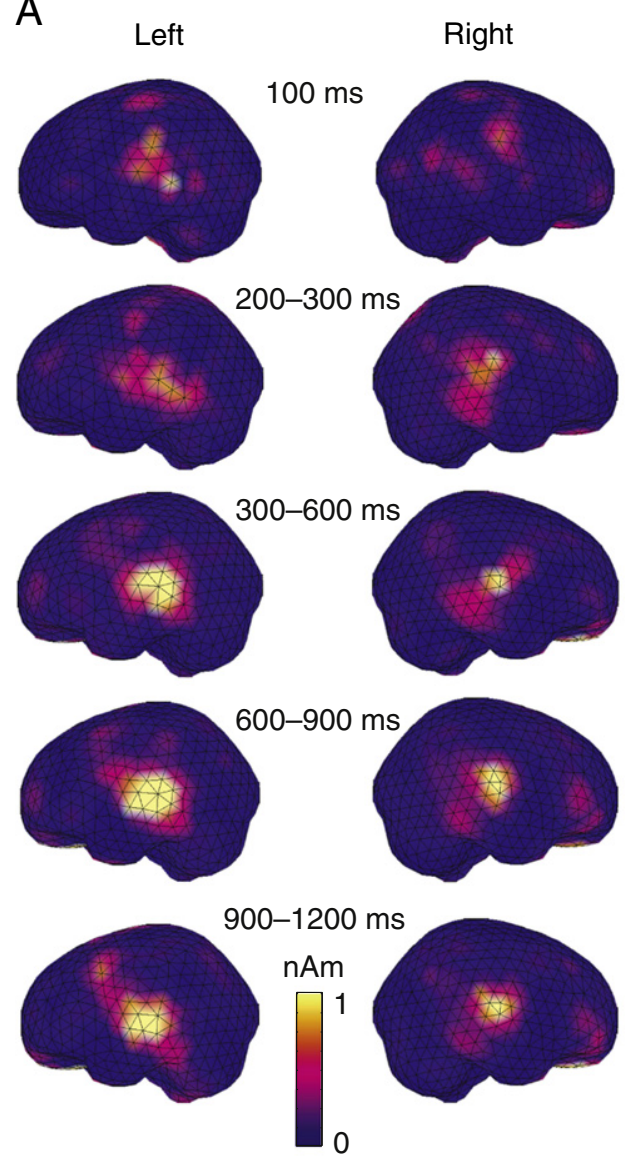

B
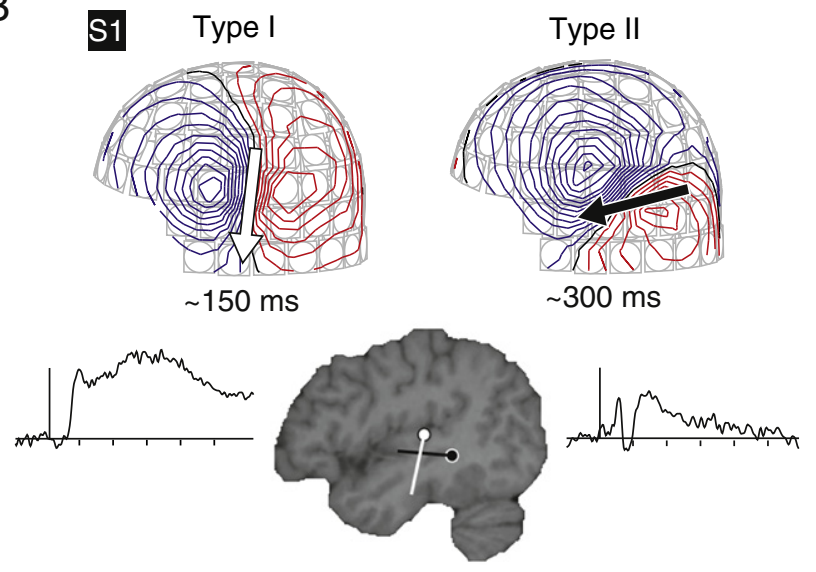

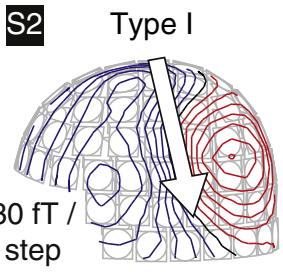

$\sim 150 \mathrm{~ms}$

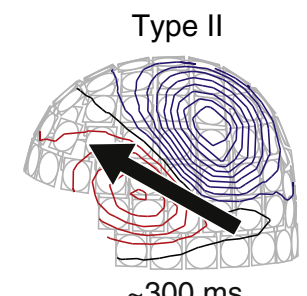

$\sim 300 \mathrm{~ms}$

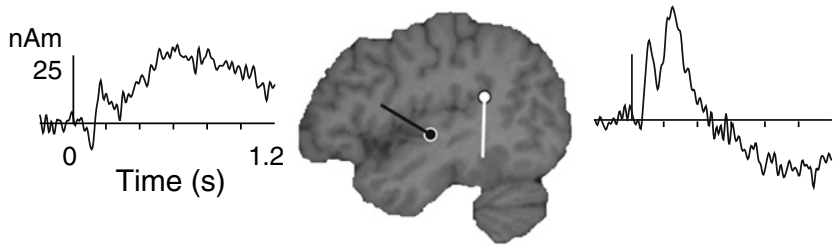

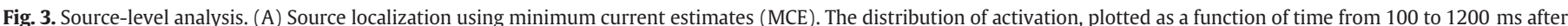

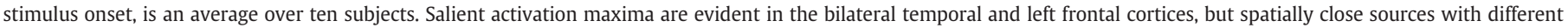

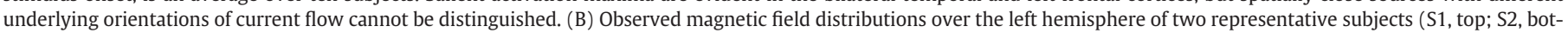

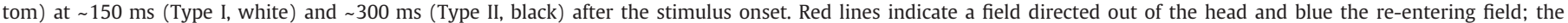

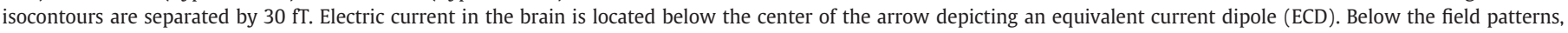

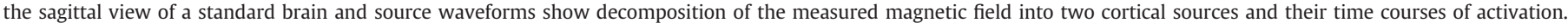

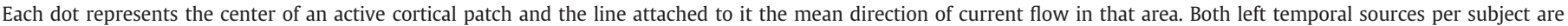
displayed. Source-level activation strength is given in nanoamperemeters (nAm).

but on Day 2 activation evoked by the Recurring items from Day 1 and New items did not differ from each other.

Finally, at 600-1200 ms, stimulus recurrence influenced activation of the Type I left temporal and the left frontal sources, similarly for both languages. Activation of the left temporal sources was significantly reduced to the Recurring stimuli compared to the Nonrecurring/New stimuli $[\mathrm{F}(1,8)=9.6, \mathrm{p}<0.05$, Recurring $14.6 \pm 3.7 \mathrm{nAm}$, Nonrecurring $16.7 \pm 3.8 \mathrm{nAm}]$. In contrast, activation of the left frontal sources was enhanced for Recurring stimuli $[F(1,5)=9.7, p<0.05$, Recurring $17.7 \pm 2.6 \mathrm{nAm}$, Nonrecurring $15 \pm 1.6 \mathrm{nAm}]$. Both recurrence effects persisted to Day 2. Evaluation of trial-by-trial correspondence between the left frontal and temporal activation of individual participants in the 600-1200 ms time window (where statistically significant experimental effects were evident for both sources) revealed that the activation strengths in these two areas were significantly negatively correlated (mean correlation $\mathrm{r}=-0.33$, range $-0.58 \ldots 0.33, \mathrm{p}<0.01$ ).

\section{Discussion}

This study demonstrated incidental learning of both native and foreign phonology when the subjects heard and reproduced word forms multiple times. Both the behavioral experiment and the main MEG experiment pointed to initial item-based learning at the level of recurring word forms rather than general learning of foreign-language (Korean) phonotactic patterns. Neural effects during word perception and encoding were observed that persisted to the following day, thus emerging as likely cortical markers of longer-term learning. Although salient activation was detected in both hemispheres, the learning effects were all lateralized to the left hemisphere, with activation attenuating in the temporal cortex and increasing in the frontal cortex.

Recognition performance was significantly better for Recurring words than for Nonrecurring words, similarly in the behavioral and MEG experiment. In the behavioral experiment with Korean word forms, repetition latencies became shorter and responses more accurate for the Recurring words after multiple presentations. In marked contrast, repetition accuracy of the Nonrecurring words did not improve, pointing to learning of the Recurring word forms rather than learning of general regularities in the foreign phonotactic system. Comparable analysis of repetition accuracy in the MEG experiment showed better performance for the Finnish pseudowords than for the Korean words, but no changes in performance during the session. For the native language items, repetition performance was near ceiling. For Korean words, the repetition accuracy remained overall markedly lower in the MEG experiment $(\sim 35 \%)$ than in the behavioral experiment ( $60 \%)$, partly due to the length of the stimuli and 
A

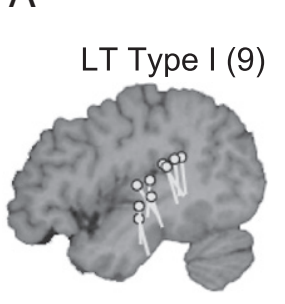

LT Type II (6)

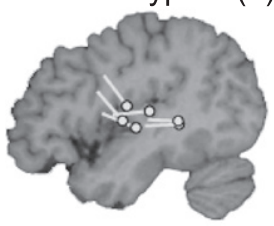

LF (6)

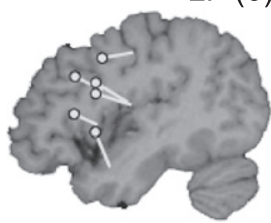

RT Type I (10)

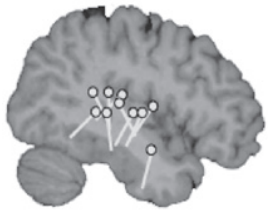

RT Type II (6)
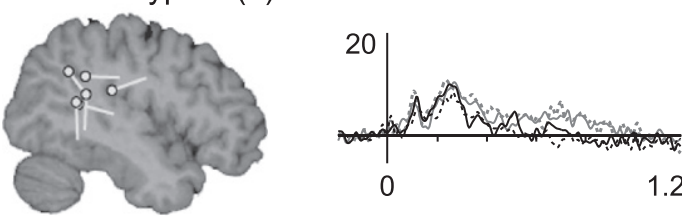

1.2

B
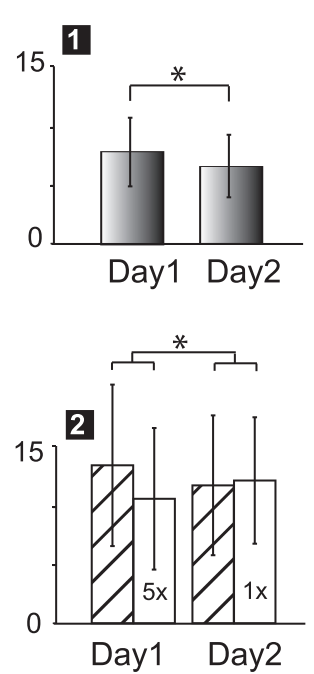

Day 1
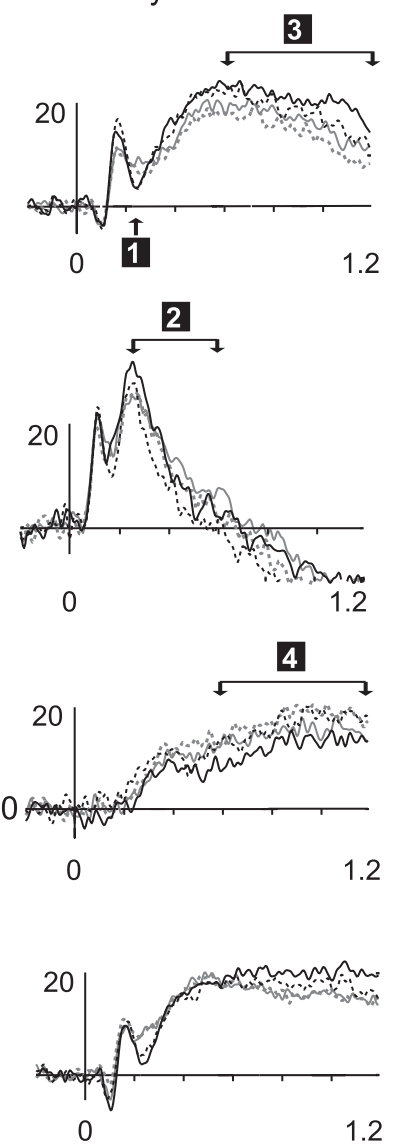

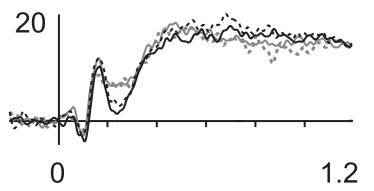

$n A m$
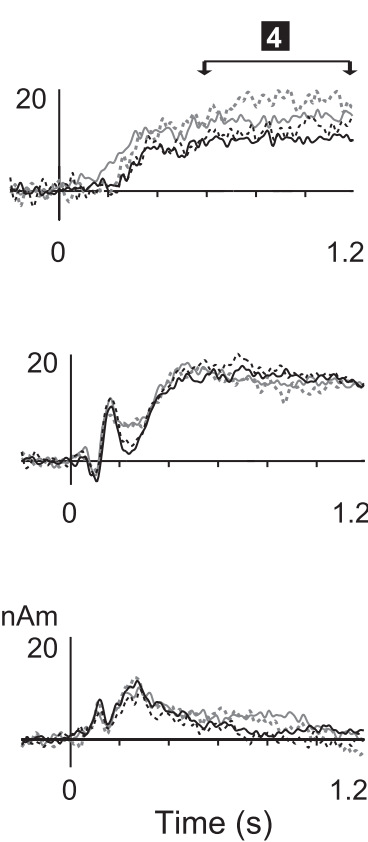

1.2
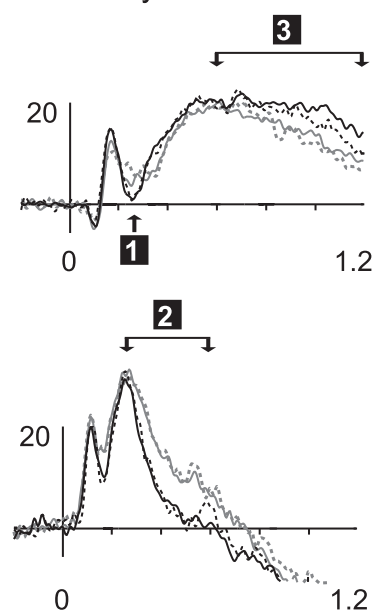
Table 2

Group-level statistical analysis results for each time window and source cluster.

\begin{tabular}{|c|c|c|c|c|c|c|}
\hline Time window & Source cluster & $\mathrm{N}$ & Effect & $\mathrm{F}$ & df & $\mathrm{p}$ \\
\hline \multirow[t]{8}{*}{$\sim 170 \mathrm{~ms}$ (peak) } & \multirow[t]{4}{*}{ LT Type I } & \multirow[t]{4}{*}{9} & Recurrence & .69 & 1,8 & .43 \\
\hline & & & Language & 5.3 & 1,8 & .051 \\
\hline & & & Day & .41 & 1,8 & .54 \\
\hline & & & Interactions & & 1,8 & n.s. \\
\hline & \multirow[t]{4}{*}{ RT Type I } & \multirow[t]{4}{*}{10} & Recurrence & .96 & 1,9 & .35 \\
\hline & & & Language & .002 & 1,9 & .97 \\
\hline & & & Day & .11 & 1,9 & .75 \\
\hline & & & Interactions & & 1,9 & n.s. \\
\hline \multirow{8}{*}{$\begin{array}{l}\sim 200 \mathrm{~ms} \text { (100 ms mean around } \\
\text { the individually defined minimum) }\end{array}$} & \multirow{4}{*}{ LT Type I } & \multirow[t]{4}{*}{9} & Recurrence & .15 & 1,8 & .71 \\
\hline & & & Language & .20 & 1,8 & .67 \\
\hline & & & Day & 6.1 & 1,8 & $.038^{*}$ \\
\hline & & & Interactions & & 1,8 & n.s. \\
\hline & \multirow[t]{4}{*}{ RT Type I } & \multirow[t]{4}{*}{10} & Recurrence & 1.6 & 1,9 & .24 \\
\hline & & & Language & 1.9 & 1,9 & .20 \\
\hline & & & Day & 3.4 & 1,9 & .097 \\
\hline & & & Interactions & & 1,9 & n.s. \\
\hline \multirow[t]{9}{*}{$300-600$ ms (mean) } & \multirow[t]{5}{*}{ LT Type II } & \multirow[t]{5}{*}{6} & Recurrence & 1.6 & 1,5 & .26 \\
\hline & & & Language & 7.5 & 1,5 & $.041^{*}$ \\
\hline & & & Day & .00 & 1,5 & .99 \\
\hline & & & Recurrence x Day & 7.5 & 1,5 & $.041^{*}$ \\
\hline & & & Other interactions & & 1,5 & n.s. \\
\hline & \multirow[t]{4}{*}{ RT Type II } & \multirow[t]{4}{*}{6} & Recurrence & 1.8 & 1,5 & .24 \\
\hline & & & Language & 1.8 & 1,5 & .24 \\
\hline & & & Day & 1.7 & 1,5 & .25 \\
\hline & & & Interactions & & 1,5 & n.s. \\
\hline \multirow[t]{12}{*}{600 - 1200 ms (mean) } & \multirow[t]{4}{*}{ LT Type I } & \multirow[t]{4}{*}{9} & Recurrence & 9.6 & 1,8 & $.015^{*}$ \\
\hline & & & Language & 2.2 & 1,8 & .18 \\
\hline & & & Day & 2.2 & 1,8 & .18 \\
\hline & & & Interactions & & 1,8 & n.s. \\
\hline & \multirow{4}{*}{ RT Type I } & \multirow[t]{4}{*}{10} & Recurrence & .68 & 1,9 & .43 \\
\hline & & & Language & 1.3 & 1,9 & .28 \\
\hline & & & Day & 2.8 & 1,9 & .13 \\
\hline & & & Interactions & & 1,9 & n.s. \\
\hline & \multirow[t]{4}{*}{$\mathrm{LF}$} & \multirow[t]{4}{*}{6} & Recurrence & 9.7 & 1,5 & $.026^{*}$ \\
\hline & & & Language & .83 & 1,5 & .40 \\
\hline & & & Day & .77 & 1,5 & .42 \\
\hline & & & Interactions & & 1,5 & n.s. \\
\hline
\end{tabular}

LT = left temporal cortex, RT = right temporal cortex, $\mathrm{LF}=$ left frontal cortex.

Statistically significant $\mathrm{p}$-values denoted with asterisk $\left({ }^{*}<.05\right)$.

likely also to the delayed and temporally constrained reproduction phase (necessitated by the MEG recording) that allowed little time for detailed motor planning and/or reconstruction of the word forms from long-term memory.

As processing of stimuli adhering to the phonotactic rules of the participants' native language and a foreign language were directly contrasted in the MEG experiment, we were able to distinguish acquisition of specific phonological forms (new in both languages) from learning of generalized phonotactic structures (new in the foreign language only). The neural effects of auditory perception and encoding were similar for the foreign (Korean) and native language (Finnish) items and, therefore, most parsimoniously interpreted as indicative of itembased learning of phonological word forms, in line with recent theories of phonological learning (e.g. Pierrehumbert, 2003). Thus, it seems that no general acquisition of the Korean phonotactic regularities was evidenced during the first exposure to this language that was completely foreign for the participants. It is reasonable to assume that a foreign language is first partly interpreted through the phonotactic system of the native language, in line with previous studies showing that foreign phonemes are at first assimilated into the native language phonemic system (e.g. Kuhl et al., 1992). In the present task, in order to encourage processing of phonetic/phonological details, the participants were asked to produce the novel forms as accurately as possible and they were quite successful at it (especially with the shorter stimuli in the behavioral experiment $-81 \%$ correct). It is, therefore, unlikely that participants would have relied solely on Finnish phoneme equivalents when trying to produce the Korean words. An alternative would be that repetition was based on a purely acoustic-phonetic analysis. The most likely case is a blend of L1 anchors for phonological memory support and freshly encoded phonetic detail (Flege, 2007).

The cortical time course of activation (Type I early-Type II-Type I late) observed in the MEG analysis agrees with that previously described in MEG studies of speech sound perception: transient activation at about $100 \mathrm{~ms}$ (typically referred to as an $\mathrm{N} 100 \mathrm{~m}$ response; Type I early), followed by sustained activation reaching the maximum at $\sim 400 \mathrm{~ms}$ (often referred to as an N400m response; Type I late), both generated in the vicinity of the auditory cortex, in the planum temporale and the adjacent superior temporal cortex (see Salmelin, 2007 for a review). In this sequence, sensitivity to speech-specific acoustic-phonetic features is detected by $50-100 \mathrm{~ms}$ (Parviainen et al., 2005; Tiitinen et al., 1999), phoneme categories by $\sim 150 \mathrm{~ms}$ (Näätänen et al., 1997; Phillips et al., 2000), lexical-semantic manipulation from $\sim 200 \mathrm{~ms}$ onwards and phonological manipulation after $\sim 450$ ms (Bonte et al., 2006; Kujala et al., 2004; Salmelin, 2007; Uusvuori et al., 2008), most effects being left-lateralized. A transient response reaching the maximum at $200-300 \mathrm{~ms}$ has also been

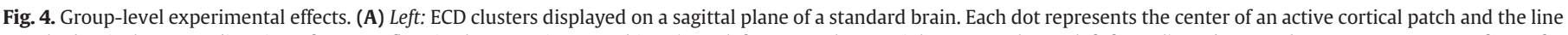

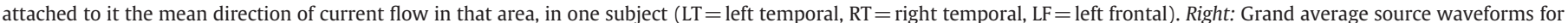

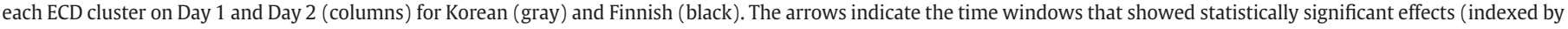

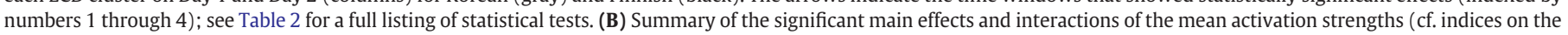
source time courses). Error bars indicate the standard error of mean. 
described, with the neural source in the superior temporal cortex and current flow almost perpendicular to that of the $\mathrm{N} 100 \mathrm{~m} / \mathrm{N} 400 \mathrm{~m}$ sources (Bonte et al., 2006; Uusvuori et al., 2008). As MEG primarily detects activity of pyramidal neurons in the sulci, the rostral alignment of the neural current suggests generation not in the supratemporal plane but in a transverse sulcus. Visualization on the individual structural MRIs places the Type II sources in the vicinity of Heschl's gyrus (HG) on the left, and consistently posteriorly to HG on the right. Sustained frontal activation during delays has additionally been reported when subjects are prepared to later reproduce a spoken stimulus (Biermann-Ruben et al., 2005).

Despite bilateral activity in the superior temporal cortex, experimental effects were observed only in the left hemisphere. A small but significant effect of measurement day was evident in the Type I temporal sources, where the transient reduction of activation around 200 ms was deeper on Day 2. The effect was not influenced by stimulus recurrence or language, thus, it does not seem specifically related to learning. Rather, it may reflect general familiarization, i.e., higher automaticity of the task on Day 2. Event-related potential (ERP) experiments have shown modulations in this time window, in the so-called P2 component, as a result of repeated exposure to novel phonological constraints, uncorrelated to behavioral improvements in discrimination accuracy (Tremblay et al., 2010); however, the cognitive functions of the P2 component remain unclear.

Sensitivity to language, as overall longer lasting activation to the unfamiliar Korean phonology than to the familiar Finnish phonology, was observed in the left-hemisphere Type II temporal sources at 300-600 ms. This time window coincides with some ERP and MEG reports on mapping of auditory input to phonology that, using meaningless stimuli as in the present study, have identified a so-called PMN (phonological mapping negativity) response, separate from the classic N400 response (Connolly and Phillips, 1994; Kujala et al., 2004). Earlier MEG studies on speech perception using stimuli that adhere to familiar phonology have found no experimental effects in this response (Bonte et al., 2006; Uusvuori et al., 2008). However, processing of a poorly mastered foreign language commonly results in stronger hemodynamic signals and longer-lasting event-related potentials (for a review, see e.g. van Heuven and Dijkstra, 2010). Here, the lack of semantic cues in either language may have emphasized (relatively low-level) speech-sensitive acoustic-phonetic processing of the auditory input that was particularly demanding for the foreign phonetic structure of Korean. The left-hemisphere Type II temporal sources also displayed sensitivity to stimulus recurrence as reduced activation at 300-600 ms in the Day 1 session (similarly for both languages), but on Day 2 the recurring items from Day 1 were no longer distinguishable from new items. This pattern seems to suggest that this effect mainly reflects short-term repetition priming in the sensory perception of novel phonological input, which underlies the initial formation of memory representations.

Longer-term learning, however, was reflected in the activation of the left-hemisphere frontal and Type I temporal sources at 600-1200 ms. The persistence of modulated activations for words that recurred multiple times on Day 1, to the next day, suggests neural plasticity beyond within-session repetition suppression (Grill-Spector et al., 2006). The effects demonstrate that even a relatively natural incidental learning task, such as simple listening to words and their subsequent reproduction, suffices to show evidence for learning proceeding beyond short-term repetition suppression to storage into long-term memory. Furthermore, the significant trial-by-trial correlation between the left frontal and Type I temporal activations point to a direct functional link between the left temporal and frontal learning effects even during the word perception phase, yielding support for a view that sensorimotor integration may be employed for establishing patterns that can support memory by rehearsal. This interpretation is in line with an ERP study (Pulvermüller et al., 2012), where left frontal activity was observed during listening to newly learned words (without repetition) only when the learning phase had involved overt repetition, but not when it had relied on passive listening. In addition to better defined articulatory-motor programs and faster access to them, the formation of more permanent memory representations facilitates maintenance in working memory, possibly reflected in the joint modulations of left frontal and Type I temporal brain responses. In a recent fMRI study (McGettigan et al., 2011), speech perception and active maintenance before overt rehearsal, contrasted with passive listening, activated both the auditory and motor cortical areas. Furthermore, activation of the planum temporale shows distinct patterns of speech rehearsal and speech perception, as determined by voxelwise analysis (Hickok et al., 2009).

The reduced left superior temporal activation to recurring pseudowords is in line with earlier fMRI/PET studies (Graves et al., 2008; Majerus et al., 2005; Rauschecker et al., 2008). In the left frontal cortex, activation was increased, instead, which is opposite to the reduced left frontal activation reported in an fMRI study of phonological learning (Rauschecker et al., 2008). This discrepancy might be explained by differences between different imaging methods or experimental designs. Notably, other fMRI/PET studies have found increased activation in specific left frontal areas when comparing overt word repetition in the second and first language of bilinguals (Klein et al., 2006) and when overtly repeating pseudowords of native or non-native syllable structure (Moser et al., 2009). These frontal effects were interpreted to reflect increased demands on the motor system and articulation. In the present study, which employed delayed reproduction, the frontal activation was detected during the perception phase, well before delayed overt vocalization. Based on previous MEG reports on cortical activation when preparing to name pictured items, prior to overt vocalization (Hultén et al., 2009; Liljeström et al., 2009; Vihla et al., 2006), the frontal effect may be interpreted as reflecting phonological planning and articulation. Another alternative interpretation is that the frontal effect could reflect the recognition of the recurring words, in accordance with a recent study suggesting a similar increase in frontal activity for recurring words that reappear several items apart in a continuous recognition paradigm (Buchsbaum et al., 2010). The precise roles of these salient experimental effects need to be adjudicated by future studies, possibly by means of dissociating articulatory from memory processes as well as auditory from phonological processes.

To conclude, substantial item-based incidental learning through word perception and overt reproduction was observed in this study similarly for native and foreign word forms, both behaviorally and cortically. Novel phonological forms were recognized better and reproduced faster and more accurately after multiple repetitions, over the course of one experimental session. Although event-related magnetic brain responses during word perception and encoding were observed bilaterally in the temporal regions, experimental effects only emerged on the left. Learning-related changes in sustained activation in the left superior temporal cortex (decrease) and left frontal cortex (increase) persisted to Day 2, thus pointing to long-term learning. These effects were similar in both a familiar phonology (Finnish) and an unfamiliar phonology (Korean). Consequently, the initial learning effects seem to be linked to experience with individual phonological word forms rather than general acquisition of the foreign phonology.

\section{Acknowledgments}

This work was supported by the Academy of Finland (National Centres of Excellence Programme 2006-2011, personal grant to RS), the Sigrid Jusélius Foundation, the Finnish Cultural Foundation, Stiftelsen för Åbo Akademi and Finnish Graduate School of Neuroscience / Doctoral Program Brain \& Mind.

\section{References}

Biermann-Ruben, K., Salmelin, R., Schnitzler, A., 2005. Right rolandic activation during speech perception in stutterers: a MEG study. NeuroImage 25 (3), 793-801. 
Bonte, M., Parviainen, T., Hytönen, K., Salmelin, R., 2006. Time course of top-down and bottom-up influences on syllable processing in the auditory cortex. Cereb. Cortex $16,115-123$.

Buchsbaum, B.R., Padmanabhan, A., Berman, K.F., 2010. The neural substrates of recognition memory for verbal information: spanning the divide between short- and long-term memory. J. Cogn. Neurosci. 23 (4), 978-991.

Connolly, J.F., Phillips, N.A., 1994. Event-related potential components reflect phonological and semantic processing of the terminal word of spoken sentences. J. Cogn. Neurosci. 6, 256-266.

Dumay, N., Gaskell, M.G., 2007. Sleep-associated changes in the mental representation of spoken words. Psychol. Sci. 18 (1), 35-39.

Edwards, J., Beckman, M.E., Munson, B., 2004. The interaction between vocabulary size and phonotactic probability effects on children's production accuracy and fluency in nonword repetition. J. Speech Lang. Hear. Res. 47, 421-436.

Ellis, N., Beaton, A., 1993. Factors affecting the learning of foreign language vocabulary: imagery keyword mediators and phonological short-term memory. Q. J. Exp. Psychol. A 46 (3), 533-558.

Flege, J.E., 2007. Language contact in bilingualism: phonetic system interactions. In: Cole, J. Hualde, J.I. (Eds.), Laboratory Phonology. Mouton de Gruyter, New York, pp. 353-382.

Forkstam, C., Elwér, Å., Ingvar, M., Petersson, K.M., 2008. Instruction effects in implicit artificial grammar learning: a preference for grammaticality. Brain Res. 1221, 80-92.

French, L.M., 2006. Phonological Working Memory and L2 Acquisition: A Developmental Study of Quebec Francophone Children Learning English. Edwin Mellen Press, Lewiston, N.Y.

Friederici, A.D., Wessels, J.M.I., 1993. Phonotactic knowledge of word boundaries and its use in infant speech perception. Percept. Psychophys. 54 (3), 287-295.

Gathercole, S.E., Baddeley, A.D., 1989. Evaluation of the role of phonological STM in the development of vocabulary in children: a longitudinal study. J. Mem. Lang. 28, 200-213.

Gathercole, S.E., 1995. Is nonword repetition a test of phonological memory or longterm knowledge? It all depends on the nonwords. Mem. Cognit. 23, 83-94.

Gathercole, S.E., Frankish, C.R., Pickering, S.J., Peaker, S., 1999. Phonotactic influences on short-term memory. J. Exp. Psychol. 25 (1), 84-95.

Gathercole, S.E., 2006. Nonword repetition and word learning: the nature of the relationship. Appl. Psycholinguist. 27, 513-543.

Graves, W.W., Grabowski, T.J., Mehta, S., Gupta, P., 2008. The left posterior superior temporal gyrus participates specifically in accessing lexical phonology. J. Cogn. Neurosci. 20 (9), 1698-1710.

Grill-Spector, K., Henson, R., Martin, A., 2006. Repetition and the brain: neural models of stimulus-specific effects. Trends Cogn. Sci. 10, 14-23.

Hari, R., 1990. Magnetic evoked fields of the human brain: basic principles and applications. Electroencephalogr. Clin. Neurophysiol. Suppl. 41, 3-12.

Hickok, G., Okada, K., Serences, J.T., 2009. Area Spt in the human planum temporale supports sensory-motor integration for speech processing. J. Neurophysiol. 101 (5), 2725-2732.

Hultén, A., Vihla, M., Laine, M., Salmelin, R., 2009. Accessing newly learned names and meanings in the native language. Hum. Brain Mapp. 30 (3), 976-989.

Hämäläinen, M., Hari, R., Ilmoniemi, R.J., Knuutila, J., Lounasmaa, O.V., 1993. Magnetoencephalography - theory, instrumentation, and applications to noninvasive studies of the working human brain. Rev. Mod. Phys. 65, 413-497.

Jusczyk, P.W., Cutler, A., Redanz, N.J., 1993. Infants' preference for the predominant stress patterns of English words. Child Dev. 64, 675-676.

Jusczyk, P.W., Luce, P.A., Charles-Luce, J., 1994. Infants' sensitivity to phonotactic patterns in the native language. J. Mem. Lang. 33, 630-645.

Karlsson, F., 2003. Finnish: An Essential Grammar. Routledge, London.

Kim, J.-Y., 2010. L2 Korean Phonology. What Matters in L2 Pronunciation? VDM Verlag Dr. Müller, Saarbrücken.

Kim, K.-O., Shibatani, M., 1976. Syllabification phenomena in Korean. Lang. Res. 12 (1), 91-98.

Klein, D., Watkins, K.E., Zatorre, R.J., Milner, B., 2006. Word and nonword repetition in bilingual subjects: a PET study. Hum. Brain. Mapp. 27, 153-161.

Kovács, G., Racsmány, M., 2008. Handling L2 input in phonological STM: the effect of non-L1 phonetic segments and non-L1 phonotactics on nonword repetition. Lang. Learn. 58 (3), 597-624.

Kuhl, P.K. Williams, K.A., Lacerda, F. Stevens, K.N., Lindblom, B. 1992. Linguistic experience alters phonetic perception in infants by 6 months of age. Science 255, 606-608.

Kujala, A., Alho, K., Service, E., Ilmoniemi, R.J., Connolly, J.F., 2004. Activation in the anterior left auditory cortex associated with phonological analysis of speech input: localization of the phonological mismatch negativity response with MEG. Cogn. Brain. Res. 21 (1), 106-113.

Liljeström, M., Hultén, A., Parkkonen, L., Salmelin, R., 2009. Comparing MEG and fMR views to naming actions, and objects. Hum. Brain Mapp. 30 (6), 1845-1856.

Lönnrot, E., 1874-1880. Finskt-Svenskt Lexicon (Swedish-Finnish Dictionary). The Finnish Literature Society, Helsinki.

Majerus, S., Van der Linden, M., Mulder, L., Meulemans, T., Peters, F., 2004. Verbal shortterm memory reflects the sublexical organization of the phonological language network: evidence from an incidental phonotactic learning paradigm. J. Mem. Lang. 51, 297-306.

Majerus, S., Van derLinden, M., Collette, F., Laureys, S., Poncelet, M., Degueldre, C., Delfiore, G., Luxen, A., Salmon, E., 2005. Modulation of brain activity during phonological familiarization. Brain Lang. 92, 320-331.

McGettigan, C., Warren, J.E., Eisner, F., Marshall, C.R., Shanmugalingam, P., Scott, S.K., 2011. Neural correlates of sublexical processing in phonological working memory. J. Cogn. Neurosci. 23 (4), 961-977.
Moser, D., Fridriksson, J., Bonilha, L., Healy, E.W., Baylis, G., Baker, J.M., Rorden, C., 2009. Neural recruitment for the production of native and novel speech sounds. NeuroImage 46, 549-557.

Mäkelä, J.P., Hari, R., 1990. Long-latency auditory evoked magnetic fields. Adv. Neurol. 54, 177-191.

Näätänen, R., Lehtokoski, A., Lennes, M., Cheour, M., Huotilainen, M., Iivonen, A., Vainio, M., Alku, P., Ilmoniemi, R.J., Luuk, A., Allik, J., Sinkkonen, J., Alho, K., 1997. Languagespecific phoneme representations revealed by electric and magnetic brain responses. Nature 385 (6615), 432-434.

Oldfield, R.C., 1971. The assessment and analysis of handedness: the Edinburgh inventory. Neuropsychologia 9 (1), 97-113.

Papagno, C., Valentine, T., Baddeley, A., 1991. Phonological short-term memory and foreign-language vocabulary learning. J. Mem. Lang. 30 (3), 331-334.

Parviainen, T., Helenius, P., Salmelin, R., 2005. Cortical differentiation of speech and nonspeech sounds at $100 \mathrm{~ms}$ : implications for dyslexia. Cereb. Cortex 15 (7), 1054-1063.

Phillips, C., Pellathy, T., Marantz, A., Yellin, E., Wexler, K., Poeppel, D., McGinnis, M., Roberts, T., 2000. Auditory cortex accesses phonological categories: an MEG mismatch study. J. Cogn. Neurosci. 12 (6), 1038-1055.

Pierrehumbert, J.B., 2003. Phonetic diversity, statistical learning, and acquisition of phonology. Lang. Speech 46 (2-3), 115-154.

Pulvermüller, F., Kiff, J., Shtyrov, Y., 2012. Can language-action links explain language laterality?: an ERP study of perceptual and articulatory learning of novel pseudowords. Cortex 48 (7), 871-881.

Rauschecker, A.M., Pringle, A., Watkins, K.E., 2008. Changes in neural activity associated with learning to articulate novel auditory pseudowords by covert repetition. Hum. Brain Mapp. 29, 1231-1242.

Roland, P.E., Zilles, K., 1996. The developing European computerized human brain database for all imaging modalities. NeuroImage 4,39-47.

Saffran, J.R., Newport, E.L., Aslin, R.N., 1996. Word segmentation: the role of distributional cues. J. Mem. Lang. 35, 606-621.

Saffran, J.R., Newport, E.L., Aslin, R.N., Tunick, R.A., 1997. Incidental language learning: listening (and learning) out of the corner of your ear. Psychol. Sci. 8, 101-105.

Salmelin, R., 2007. Clinical neurophysiology of language: the MEG approach. Clin. Neurophysiol. 118, 237-254.

Salmelin, R., 2010. Multi-dipole modeling in MEG. In: Hansen, P.C., Kringelbach, M.L., Salmelin, R. (Eds.), MEG: An Introduction to Methods. Oxford University Press, New York, pp. 124-155

Schormann, T., Henn, S., Zilles, K., 1996. A new approach to fast elastic alignment with applications to human brains. Lect. Notes Comput. Sci. 1131, 337-342.

Service, E., 1992. Phonology, working memory and foreign-language learning. Q. J. Exp. Psychol. 45A (1), 21-50.

Service, E., Kohonen, V., 1995. Is the relation between phonological memory and foreign-language learning accounted for by vocabulary acquisition? Appl. Psycholinguist. 16, 155-172

Storkel, H.L., Armbrüster, J., Hogan, T.P., 2006. Differentiating phonotactic probability and neighborhood density in adult word learning. J. Speech Lang. Hear. R. 49,1175-1192.

Storkel, H.L., 2009. Developmental differences in the effects of phonological, lexical and semantic variables on word learning by infants. J. Child. Lang. 36, 291-321.

Storkel, H.L., Lee, S.-Y., 2011. The independent effects of phonotactic probability and neighbourhood density on lexical acquisition by preschool children. Lang. Cognitive. Proc. 26, 191-211.

Tamminen, J., Gaskell, M.G., 2008. Newly learned spoken words show long-term lexical competition effects. Q. J. Exp. Psychol. 61 (3), 361-371.

Thorn, A., Gathercole, S.E., 1999. Language-specific knowledge and short-term memory in bilingual and non-bilingual children. Q. J. Exp. Psychol. A 52 (2), 303-324.

Tiitinen, H., Sivonen, P., Alku, P., Virtanen, J., Näätänen, R., 1999. Electromagnetic recordings reveal latency differences in speech and tone processing in humans. Cogn. Brain Res. 8 (3), 355-363.

Tremblay, K.L., Inoue, K., McClannahan, K., Ross, B., 2010. Repeated stimulus exposure alters the way sound is encoded in the human brain. PLoS One 5 (4), http:// dx.doi.org/10.1371/journal.pone.0010283.

Uusvuori, J., Parviainen, T., Inkinen, M., Salmelin, R., 2008. Spatiotemporal interaction between sound form and meaning during spoken word perception. Cereb. Cortex 18 (2), 456-466.

Uutela, K., Hämäläinen, M., Somersalo, E., 1999. Visualization of magnetoencephalographic data using minimum current estimates. Neurolmage 10 (2), 173-180.

van Heuven, W.J., Dijkstra, T., 2010. Language comprehension in the bilingual brain: fMRI and ERP support for psycholinguistic models. Brain Res. Rev. 64 (1), 104-122.

Warker, J.A., Xu, Y., Dell, G.S., Fisher, C., 2009. Speech errors reflect the phonotactic constraints in recently spoken syllables, but not in recently heard syllables. Cognition $112,81-96$

Vihla, M., Laine, M., Salmelin, R., 2006. Cortical dynamics of visual/semantic vs. phonological analysis in picture confrontation. Neurolmage 33, 732-738.

Woods, R.P., Grafton, S.T., Watson, J.D.G., Sicotte, N.L., Mazziotta, J.C., 1998. Automated image registration. II. Intersubjects validation of linear and nonlinear models. J. Comput. Assist. Tomogr. 22, 153-165.

Zamuner, T.S., 2009. Phonotactic probabilities at the onset of language development: speech production and word position. J. Speech Lang. Hear. Res. 52, 49-60.

Zhang, Y., Kuhl, P.K., Imada, T., Kotani, M., Tohkura, Y., 2005. Effects of language experience: neural commitment to language-specific auditory patterns. NeuroImage 26, 703-720 